\title{
Research on Environmental Art in Design of Urban Underground Corridor
}

\author{
Yu Peng \\ Wuchang Institute of Technology, Wuhan, Hubei, 430065
}

Keywords: Environmental Art, Urban Underground Corridor, Structural Design

\begin{abstract}
City underground integrated corridor refers to the same artificial space in the layout of a variety of urban pipelines, thus forming an intensive, modern as one of the infrastructure, is the future direction of urban construction and development. Based on this, the general design of urban underground integrated corridor project is analyzed and discussed.
\end{abstract}

\section{Introduction}

Underground integrated corridor according to its different lines, can be divided into trunk integrated corridor, feeder integrated corridor, cable integrated corridor (cable trench) 3 kinds. Trunk integrated corridor is generally located in the middle of the road below, responsible for the distribution of integrated corridor to provide distribution services, the main accommodation for the communications, cable television, electricity, gas, water, etc., and some integrated corridor will rain, sewage system The Its characteristics for the structural section size, deep soil, the system is stable and large amount of delivery, with a high degree of safety, maintenance and testing requirements. The main channel is the pipeline, the main line of communication for the communication, cable television, electricity, gas, water and other direct services of the pipeline, the structure of the main line Section is mostly rectangular. Its characteristics for the effective cross-section is small, the construction cost is less, the system stability and the security is higher. Cable integrated corridor is generally buried in the sidewalk, the pipeline into the power, communications, cable television, pipeline direct supply of the end user. Its characteristics for the space section is small, buried depth, construction and construction costs less, do not have ventilation, monitoring and other equipment, in the maintenance and management is relatively simple.

The integrated corridor is divided into rectangular composite corridor, circular integrated corridor and profiled integrated corridor. It is usually designed according to the type, quantity, construction method, underground space and local economic situation of the incorporated municipal pipeline.

\section{General Rules for Plane Layout of Underground Integrated Corridors}

1) with urban functional zoning, construction land layout and road network planning to adapt; 2) should be combined with the status of urban underground pipelines in urban roads, rail transportation, water, rain, sewage, reclaimed water, natural gas, heat, electricity, Planning and underground pipeline integrated planning based on the layout; 3) should be underground traffic, underground commercial development, underground air defense facilities and other related construction projects; 4) integrated corridor for the conditions: busy transportation or underground pipeline more Urban core area, the central business district, underground space, high-intensity into a film focused on the development zone, important square, the main road intersection, roads and railways, the city's main road and with rail transit, underground roads, urban underground complex and other construction projects; Or the intersection of rivers, river tunnels, etc .; road width is difficult to meet the direct laying of a variety of pipeline sections; important public space; not excavation road sections. 5) should be arranged on both sides of the road on the side of the large demand for public pipelines; 6) as far as possible to meet the integrated corridor and other pipeline 
cross requirements; 7) integrated pipe access line length is shorter; 9) fully meet the requirements of the road planning on the integrated pipe ducts; 10) integrated corridor feeding port, vents, entrances and other facilities and road landscape and the road and the two sides of the road and the two sides of the building; The combination of functions;

\section{Problems and Solutions}

China's comprehensive corridor has been a certain degree of attention and achieved some development results in the latest release of the "guidance" also from the overall planning, orderly construction, strict management and support of these four aspects of the proposed feasible feasible 10 Implementation measures. However, due to the development of integrated corridor is not mature, so there must be a number of problems.

The integrated corridor is an underground space in which two or more pipelines are collected. The operating characteristics of the various pipelines are different. The main interests of the pipeline are different and the layout design is different. Therefore, the cooperation between the organizations and the organizations File data on the existence of a certain degree of difficulty. In the face of the interests of various institutional departments and the division of authority, we must set up a special management department, to develop a unified layout design. In order to better coordinate the various organizational departments, we can refer to Germany and Japan. They set up a common ditch management department, mainly to undertake the construction of a common ditch, and in several decades several times revised the relevant laws and regulations. Unified planning and coordination of the work must be completed by the corresponding government departments, other relevant departments to actively cooperate with their work. Not only improve the efficiency of the work, the interests of competition is also resolved, greatly increasing the utilization of underground resources. In the general underground integrated pipeline project, it is often a variety of professional pipeline plan is superimposed as a whole, and then in accordance with certain rules to determine the relative position between them and elevation (principle), and finally only draw the key position Section view. The design drawings presented in this way are two-dimensional, even if there are annotations can only be counted as 2. 5-dimensional, so there will be the possibility of various pipeline settings conflict. Since there is a special common ditch management department, it is entirely possible to organize other departments to carry out three-dimensional pipeline design through the department, mainly to implement the integrated design of all underground equipment such as pipeline, corridor, import and export, so that it will solve the pipeline more effectively Equipment conflict problem.

Compared with the traditional underground pipeline buried in the way, the construction of underground corridor will involve the ground coordinate datum to the underground problem, and mountain tunnels, mines, subways and other underground works are more similar. The transmission of the coordinates of the problem has become a comprehensive corridor corridor through the main problem, therefore, choose a suitable method of contact measurement is particularly important. Common contact measurement methods are: contact triangular method, wire orientation method, vertical instrument point method and gyroscope orientation method. The triangular method is a traditional method of measuring the shaft, although the principle is simple, but its existence is heavy, the operation is more complicated, the operation time is long, the labor intensity is big, the influence of the external environment is affected, the precision is not easy to improve and so on. Wire orientation method is not susceptible to on-site construction interference, calculation is convenient, can be tightly adjusted and can make judgments on the accuracy, but the wire mesh is poor, demanding conditions for observation. The principle of vertical spotting is simple, easy to observe, quick and easy to carry out strict adjustment and evaluation accuracy, but the actual operation of the process of vertical projection to the observation station when the difficulty is large. With the gyro total station orientation accuracy is getting higher and higher, gyro directional method has gradually replaced the traditional shaft contact measurement method. The gyro total station is a polar azimuth that senses the angular force of the earth by rotating the gyro motor at high speed, and then the true north direction of any point of the earth can be measured, whereby the coordinate 
azimuth of the underground conductor can be measured. Since the angular momentum of the Earth's rotation is constant, the azimuth of any conductor edge measured by the gyro total station is also accurate, and there is no error accumulation. Compared with other shafts, the gyro orientation method has the advantages of short orientation time, simple observation operation, little influence on construction work of construction unit and high precision. Therefore, the gyro orientation method can provide accurate coordinate azimuth reference for the underground plane control network, so as to ensure the correct passage of the underground corridor.

\section{Integrated Corridor Design}

(1) The construction of the urban underground integrated corridor project shall conform to the principles and objectives of "integrating urban planning, construction, social and economic development, urban landscape, technology, infrastructure and road traffic as soon as possible and effectively." (2) in different circumstances, should take a comprehensive set of corridor facilities, can be busy in the traffic or engineering lines more motorway, the pipeline is effectively buried. Through a reliable means of action, with the new three-dimensional cross-engineering lots. Construction should pay attention to the excavation of the road, for its final co-ordination, can effectively radiation the pipeline in different regions to ensure the overall results. (3) integrated corridor project to combine road traffic and a variety of municipal utilities pipeline requirements, to set up professional project planning, for the competent authorities to develop better management requirements. When the integrated corridor layout arrangements meet the maintenance conditions, should be consistent with the characteristics of economic and rational, and in the effective settings, refer to the pipeline branch characteristics. Maintenance personnel to set up the pipeline to the transmission port. (4) integrated corridor need to consider the power supply and distribution, ventilation, water supply and drainage and other industry systems supporting equipment, to achieve a comprehensive system planning, integrated corridor in the construction, one step, do all kinds of public pipelines Development laying, to achieve the effective construction of civil construction. (5) To reduce the investment in the project, save the underground space of the lower part of the road, the main road integrated corridor is considered to be arranged in the central green belt of the road, the secondary road, the branch integrated corridor to consider under the sidewalk, at the same time, Set aside enough access to all types of pipelines. (6) should be coordinated with underground traffic, underground commercial development, underground air defense facilities and other related construction projects. (7) integrated corridor should be placed in the road on both sides of the block on the larger demand side of the public pipeline. (8) integrated corridor should be set up monitoring center, monitoring center should be adjacent to the public building construction.

The cross-sectional dimensions of the integrated corridor shall be based on the space required for the maintenance of the pipelines, the maintenance and management channels, the operating space and the space required for lighting, ventilation, drainage, fire and other facilities, taking into account the structure of the special parts, And other arrangements, and consider the location of the geological conditions, along the line conditions, transportation and other construction conditions, sewers and other underground buried objects and the surrounding buildings and other conditions, the comprehensive analysis of the economic rational section after the decision. Integrated corridor cross-section form is divided into rectangular integrated corridor, circular integrated corridor and profiled integrated corridor. The integrated corridor is divided into single, double and multi cabins according to the number of compartments.

Comprehensive corridor should follow the underground structure waterproof design "to prevent the main, rigid and flexible combination, multi-channel fortification, according to local conditions, comprehensive management" principle. Integrated corridor waterproof rating of not less than two. Comprehensive corridor structure waterproof mainly used in the form of concrete from the waterproof, waterproof structure of the use of polymer waterproofing membrane for processing. Integrated corridor leakage fortification of the key parts of the deformation joints, vents, lifting mouth, pipeline access holes and so on.

Integrated corridor nodes include integrated corridor outlet, vents, escape, monitoring center 
connection channel, hoisting mouth, intersection and so on. Corridor set vent, about 200m set a place, the vent is located at both ends of the fire partition, set the mechanical exhaust fan. In order to facilitate the maintenance and replacement of the pipeline in the corridor, the escape of the fire, the integrated corridor of each of the corridors, Fire partition are set up escape mouth and repair mouth, escape and repair mouth about $200 \mathrm{~m}$ set a place. In the integrated corridor and integrated corridor at the intersection, generally have the following two methods: (1) integrated corridor in this arrangement for the upper and lower layers, to solve the pipeline cross-processing. (2) the integrated corridor in the plane to start, the pipeline from a level to achieve cross.

\section{Conclusion}

The design of urban pipeline integrated corridor is the main direction of urban future construction and development, not only can meet the requirements of the recent use, but also can meet the basic requirements of future development. Effectively control the pipeline buried and damage caused by the road and a variety of pipeline construction on the impact of urban image. In this paper, the actual project as an example, the general design of the underground integrated pipeline project was analyzed, the design of the main points were analyzed for the accumulation of similar design experience.

\section{References}

[1] Zhao Yi. Study on the construction technology of urban underground integrated corridor [J]. Science and Technology Wind. 2017 (18)

[2] Zhang Xi, Wang Hailin, Guan Weixi. Brief description of a multi-functional design of underground integrated corridor [J]. Value Engineering. 2017 (24)

[3] Li Li. On the urban underground integrated corridor construction technology research [J]. Building materials and decoration. 2017 (19)

[4] Han Jiatong. Study on key technology of design and construction of urban underground integrated corridor [J]. Building Knowledge. 2017 (08)

[5] Yao Shoulong, Wang Zhihe. On the urban underground integrated corridor construction technology research [J]. Green building materials. 2017 (01) 